\title{
Effect of the Spiritist "passe" energy therapy in reducing anxiety in volunteers: A randomized controlled trial
}

\author{
Ricardo de Souza Cavalcante ${ }^{\text {, }}$ Vanessa Burgugi Banin ${ }^{\mathrm{b}}$, \\ Niura Aparecida de Moura Ribeiro Paula ${ }^{c}$, Solange Ramires Daher ${ }^{c}$, \\ Marta Cassoni Habermann ${ }^{\mathrm{d}}$, Francisco Habermann ${ }^{\mathrm{b}}$, Ariane Moyses Bravin ${ }^{\mathrm{b}}$, \\ Carlos Eduardo Capelasso da Silva ${ }^{\mathrm{b}}$, Luis Gustavo Modelli de Andrade ${ }^{\mathrm{b}, *}$ \\ ${ }^{a}$ Department of Tropical Medicine-UNESP, Univ. Estadual Paulista, Brazil \\ ${ }^{\mathrm{b}}$ Department of Internal Medicine-UNESP, Univ. Estadual Paulista, Brazil \\ c Department of Pediatrics-UNESP, Univ. Estadual Paulista, Brazil \\ ${ }^{\mathrm{d}}$ Department of Dermatology-UNESP, Univ. Estadual Paulista, Brazil
}

\section{A R T I C L E I N F O}

\section{Article history:}

Received 3 February 2016

Received in revised form 28 April 2016

Accepted 4 May 2016

Available online 6 May 2016

\section{Keywords:}

Anxiety

Complementary therapies

Energy therapies

Spiritism

Therapeutic touch

Spiritual healing

\begin{abstract}
A B S T R A C T
Background: In Brazil, one of the most used energy therapies is the Spiritist "passe", which is practiced by Spiritist healers. Although experimental studies have demonstrated the effectiveness of different energy therapies in reducing anxiety and pain, little is known about the effect of the Spiritist "passe" on health outcomes. Therefore, the present study aimed at evaluating the effectiveness of "passe" energy therapy in reducing anxiety symptoms.

Methods/design: In this prospective, randomized controlled trial, participants were randomly allocated into two groups: Intervention ( 8 weekly Spiritist "passe" sessions, $\mathrm{n}=23$ ), and Control (8 weekly sham Spiritist "passe" sessions, $\mathrm{n}=27$ ). Anxiety was assessed using the Trait Anxiety Inventory (STAI-trait). Results: Of 97 individuals screened, 50 were included in the final analysis. Decreasing STAI-trait anxiety scores were observed in both groups throughout the study ( $p<0.0001)$. By the end of the study, $17 \%$ and $63 \%$ of intervention and control participants, respectively, still met the criterion for anxiety $(\mathrm{p}=0.001)$. However, anxiety reduction was more accentuated in the Spiritist "passe" group $(\mathrm{p}=0.02)$.

Conclusion: In this small pilot study, anxiety was more markedly reduced in participants receiving the Spiritist "passe" than in controls, warranting larger trials. Trial Registration: NCT02376959.
\end{abstract}

(c) 2016 Elsevier Ltd. All rights reserved.

\section{Introduction}

The use of complementary medicine has increased significantly worldwide. In the United States, up to $40 \%$ of adults use some form of complementary therapy, ${ }^{1,2}$ including energy therapies, such as qigong, Johrei, ${ }^{3}$ polarity therapy, pranic healing, Reiki, ${ }^{4}$ and Therapeutic Touch. These therapies are based on a purported modification of the energy fields that surround and penetrate the human

\footnotetext{
* Corresponding author at: Department of Internal Medicine-UNESP, Univ. Estadual Paulista, Rubião Jr, s/n, Botucatu, SP, 18.618-970, Brazil.

E-mail addresses: mip.ricardo@gmail.com (R. de Souza Cavalcante), Vanessa_banin@yahoo.com.br (V.B. Banin),niurapadula@hotmail.com (N.A. de Moura Ribeiro Paula), daher@fmb.unesp.br (S.R. Daher), marta.haber@gmail.com (M.C. Habermann), fhaber@uol.com.br (F. Habermann), arianemoyses@hotmail.com (A.M. Bravin),c_eduardo_c@hotmail.com (C.E.C. da Silva), landrade@fmb.unesp.br (L.G.M. de Andrade).
}

body which are supposedly involved in the process of health and illness.

The application of such therapy modalities involves touching or the laying on of hands to affect energy fields, but their effectiveness remains unclear. The effects of energy therapies have been demonstrated in experimental studies using animal models and cell cultures. $^{5-8}$ Johrei has been reported to be effective in improving sleep in sleep-interrupted mice. ${ }^{6}$ and in reducing the growth of tumor cells in vitro ${ }^{7}$ Therapeutic Touch has been suggested to increases DNA synthesis, differentiation and mineralization in human osteoblasts in culture. ${ }^{8}$

Clinical studies, in contrast, have yielded more conflicting results, due to differences in methods, endpoints and sample sizes. ${ }^{9-11}$ According to a meta-analysis of distant healing (prayer, mental healing, Therapeutic Touch, or spiritual healing), the methodologic limitations of several studies make it difficult to draw definitive conclusions about the efficacy of distant healing. ${ }^{9}$ 
A meta-analysis of human randomized controlled trials of nontouch biofield therapy also showed no conclusive results because low sample sizes precluded drawing robust conclusions. ${ }^{10}$ Reiki is the most extensively studied energy therapy technique. According to Thrane et al., there is evidence to suggest that Rieki is effective in reducing anxiety and pain. ${ }^{12}$ On the other hand, Joyce et al., in another meta-analysis, concluded that evidence demonstrating that Reiki reduces anxiety and depression is insufficient. ${ }^{11}$ Thus, despite the promising results reported to date, further studies with appropriate design and sample size are necessary to demonstrate the effectiveness of energy therapies.

In Brazil, one of the most used energy therapies is spiritual healing, also known as Spiritist "passe", which is practiced by Spiritist healers. Spiritism is very common in Brazil, both as a religion and a philosophy, and the Spiritist "passe" (laying on of hands) has been used to treat several conditions, including psychiatric disorders. ${ }^{13,14}$ Scientific investigations on this type of energy therapy have been conducted over the last decade. ${ }^{14-16}$ However, unlike Reiki, ${ }^{12}$ and Johrei ${ }^{3,17}$ there are no clinical studies on the Spiritist "passe" as an energy therapy. Therefore, the hypothesis of this study was that the Spiritist "passe" is an energy therapy that reduces the symptoms of anxiety and depression, and thus improves the quality of life of individuals with anxiety disorders.

\section{Study objectives}

\subsection{Primary objective}

To evaluate the effectiveness of a 8-week Spiritist "passe" therapy in reducing anxiety in individuals with symptoms of anxiety, compared to a control group.

\subsection{Secondary objectives}

To evaluate the effectiveness of a 8-week Spiritist "passe" therapy in reducing depression symptoms, and improving quality of life among study participants compared to a control group.

\section{Methods and design}

This single-center, prospective, randomized controlled trial was approved by the institutional review board (Ethics Committee) under number 31078414.5.0000.5411.

The study was conducted according to good clinical practices and the Declaration of Helsinki. Informed consent was obtained from all participants before enrollment. Trial Registration: NCT02376959.

\subsection{Study population}

Potential participants were recruited through the Botucatu Medical School Press Service via newspaper, magazine and radio advertisement. Eligibility was established during a screening interview according to the following criteria: 18 years of age or above, and Trait Anxiety Inventory (STAI-Trait) score greater than 41, which defined anxiety. This score corresponds to the 51 st percentile of the Brazilian population, used as the cut-off for detection of clinical anxiety symptoms. Individuals undergoing medical treatment, psychological counseling or psychiatric care for anxiety or depression were not included.

\subsection{Randomization procedure}

Participants were randomized on a $1: 1$ basis, according to a computer-generated randomization sequence obtained at www.

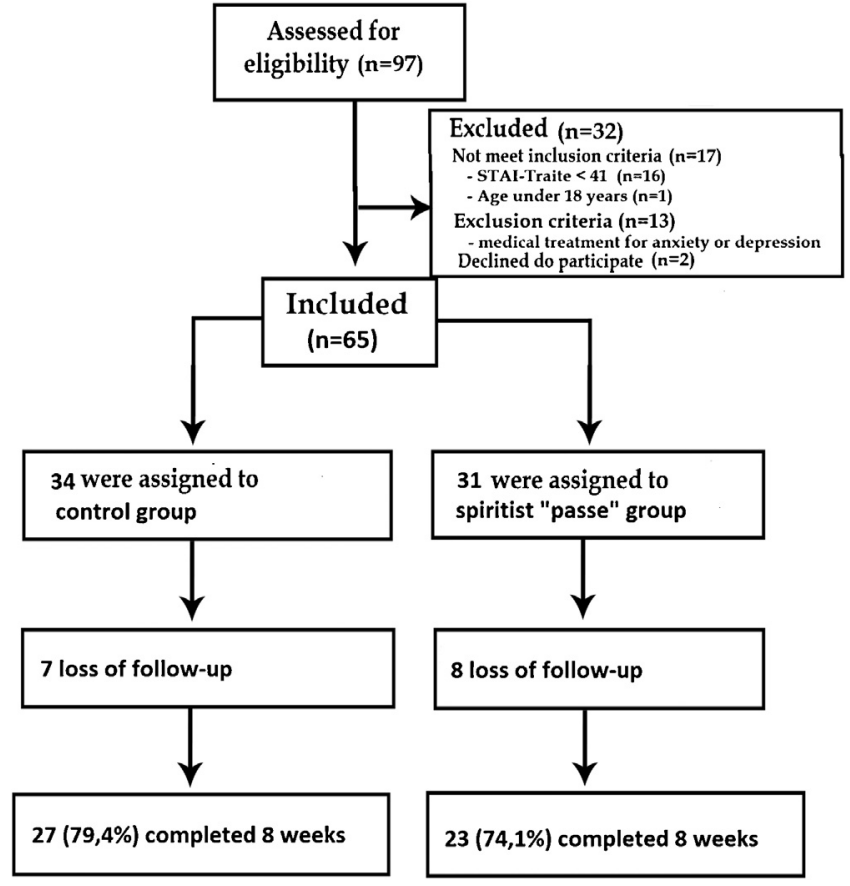

Fig. 1. Study flowchart.

randomization.com. The sequence was used in sequentially numbered opaque envelopes.

\subsection{Intervention}

This was a two-arm trial with one intervention group (Spiritist "passe") and one control group (sham "passe"). Participants from both groups underwent weekly therapy sessions for 8 weeks. Only one absence was allowed during the study period. Data were collected at baseline, 4 weeks and 8 weeks.

\subsection{Therapy sessions}

In both groups, therapy sessions consisted of relaxation with classical music for 30 min followed by the application of a "passe" or its simulation. All sessions took place in a dim lighted room, with study participants being blindfolded. Both groups received treatment at the same time and in the same room. Study participants were blinded as to whether sham or actual "passe" therapy was administered.

\subsubsection{Intervention group (Spiritist "passe")}

Participants in this group underwent 8 weekly Spiritist "passe" sessions. The Spiritist "passe" is described as an "energy transfusion" changing the cellular field, and a "psychic transfusion of energy". ${ }^{16,18}$ Spiritist therapists are authorized to perform in Spiritist Centers based on ability. Both therapists taking part in this study are affiliated to the São Paulo State Spiritist Federation, and have over 5 years of experience. After a relaxation period, the participants remained blindfolded in the supine position in a quiet dim room. Therapists held both their hands in the classic Spiritist 'passe' position $10-15 \mathrm{~cm}$ above the patient's head. The hands were then slowly lowered longitudinally from head to legs with a semi circular movement. The participant's body was touched at no time. Upon reaching the leg region, the "passe" giver joined the hands together, and repeated the same series of movements for $5 \mathrm{~min}$. Throughout the intervention procedure, the therapist remained silent and focused on healing the patient. The "passe" was administered for 


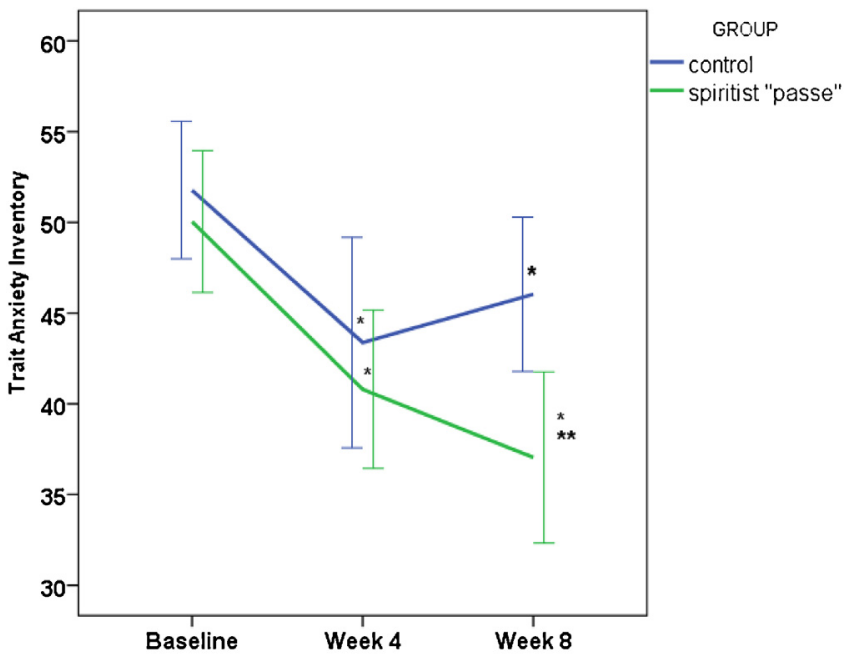

Fig. 2. Trait Anxiety Inventory scores in anxiety participants receiving the Spiritist "passe" (green line) and controls (blue line) over the eight weeks of study. ${ }^{*} \mathrm{p}<0.0001 \times$ baseline; ${ }^{* *} \mathrm{p}=0.017 \times$ control group. (For interpretation of the references to color in this figure legend, the reader is referred to the web version of this article.)

5 min, which is the average time of a "passe"session in most Spiritist Centers. ${ }^{18}$

\subsubsection{Control group}

This group underwent 8 sessions of sham Spiritist "passe" (one session per week) given by sham therapists, with no Spiritist training or prior knowledge on laying on of hands techniques such as Reiki, Johrei or Therapeutic Touch. Sham therapists were previously trained to simulate the actual "passe" protocol. They were instructed to repeat the same movements made by actual therapists, to remain silent throughout the 5-min intervention period, and not to focus on healing the patient.

\subsection{Outcomes}

\subsubsection{Primary outcome measure}

The primary outcome measure was anxiety symptoms as assessed through the Trait Anxiety Inventory (STAI-trait). This inventory was developed by Spielberger et al., ${ }^{19}$ and its Portuguese version was validated by Biaggo. ${ }^{20}$ Each STAI-trait scale consists of 20 items that measure anxiety severity and frequency on a 4-point scale. Scores range from 20 to 80 , with higher scores indicating greater levels of anxiety.

\subsubsection{Secondary outcome measures}

Secondary outcome measures included depression symptoms as assessed through the Beck Depression Inventory (BECK), and quality of life evaluated through the World Health Organization Abbreviated Instrument for Quality of Life Assessment (WHOQOLBREF).

\subsection{Beck Depression Inventory}

The Beck Depression Inventory is used for measuring the severity of depression. ${ }^{21}$ Higher total scores indicate more severe depressive symptoms. The inventory version validated for the Brazilian population by Gorenstein and Andrade ${ }^{22}$ was used.

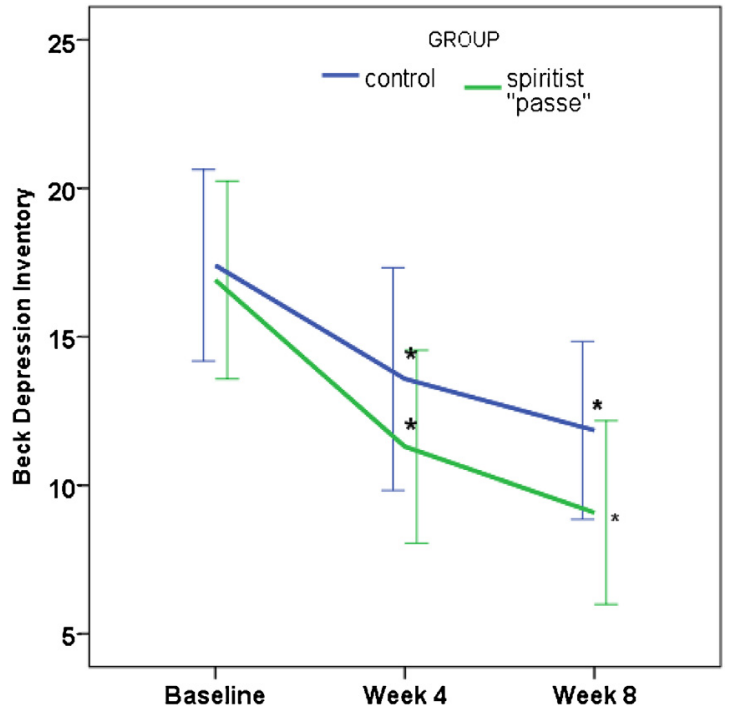

Fig. 3. Beck Depression Inventory scores in anxiety participants receiving the Spiritist "passe" (green line) and controls (blue line) over the eight weeks of study ${ }^{*} \mathrm{p}<0.0001 \times$ baseline. (For interpretation of the references to color in this figure legend, the reader is referred to the web version of this article.)

\subsection{WHOQOL-BREF}

The WHOQOL-BREF is an abbreviated version of WHOQOL$100^{23}$ used to assess quality of life. The WHOQOL-BREF consists of 26 items rated on a 5-point scale that measures the following four domains: physical health, psychological health, social relationships, and environment. Higher scores indicate better quality of life. The WHOQOL-BREF validated Portuguese version was used in this study. $^{24}$

\subsection{Measures}

Data on age, gender, race, religion and religiousness were collected at baseline. Religiousness was assessed using the Duke University Religion Index (DUREL) ${ }^{25}$ in its validated Portuguese version. ${ }^{26}$ DUREL is a five-item scale that measures the three major dimensions of religiosity (organizational, nonorganizational, and intrinsic religiosity). Higher scores are associated with lower levels of religiosity.

Trait Anxiety Inventory (STAI-trait), Beck Depression Inventory (Beck) and WHOQOL-BREF scores were measured at baseline (first session), 4 weeks, and 8 weeks (end of the study).

\subsection{Statistical analyses}

\subsubsection{Sample size}

Based on prior research evaluating Reiki for anxiety, ${ }^{9,14} 20 \%$ and $60 \%$ reductions in anxiety symptoms were anticipated to occur over 8 weeks in the intervention and control groups, respectively. Assuming alpha $=0.05$ and beta $=0.8$, a sample of 46 participants was estimated. In order to compensate for possible losses to follow up, the sample size was increased by $25 \%$, totalling 60 participants.

Statistic analyses were performed using the SPSS 20 (SPSS Inc.) statistics package. Descriptive methods were used to compare groups, to describe participants' characteristics, and participation and dropout rates. Continuous variables were assessed using a $t$-test for parametric data and the test of Mann-Whitney for nonparametric data. Categorical variables were analyzed using the Chi-square test or Fisher's exact test, when appropriate. Primary and secondary outcomes were analyzed based on the intentto-treat principle. Change in primary (STAT-trait) and secondary 
Table 1

Baseline characteristics of anxiety participants receiving the Spiritist "passe" and controls.

\begin{tabular}{|c|c|c|c|c|}
\hline Characteristic & & Control $(n=27)$ & Spiritist "passe" $(\mathrm{n}=23)$ & $\mathrm{p}$ \\
\hline Age (years), mean (SD) & & $47 \pm 16$ & $44 \pm 15$ & 0.52 \\
\hline Female & & $70.4 \%$ & $82.6 \%$ & 0.31 \\
\hline White Race & & $100 \%$ & $100 \%$ & 1.0 \\
\hline \multirow[t]{5}{*}{ Religion } & Atheist & $3.8 \%$ & $4.3 \%$ & \\
\hline & Catholic & $61.5 \%$ & $60.9 \%$ & 0.99 \\
\hline & Protestant & $0 \%$ & $0 \%$ & \\
\hline & Spiritist & $30.8 \%$ & $30.4 \%$ & \\
\hline & Others & $3.8 \%$ & $4.3 \%$ & \\
\hline \multicolumn{5}{|l|}{ Baseline scores } \\
\hline STAI-Trait, mean (SD) & & $52 \pm 10$ & $50 \pm 9$ & 0.51 \\
\hline DUREL (organizational religiosity), Median [percentile 25\% and 75\%] & & $3[2-4]$ & $4[2-4]$ & 0.93 \\
\hline DUREL (non-organizational religiosity), Median [percentile 25\% and 75\%] & & $2[2,3]$ & $2[2-5]$ & 0.65 \\
\hline DUREL (intrinsic religiosity), Median [percentile 25\% and 75\%] & & $5[4-7]$ & $5[4-7]$ & 0.82 \\
\hline BECK, mean (SD) & & $17 \pm 8$ & $17 \pm 8$ & 0.82 \\
\hline WHOQOL-BREF (physical health), Mean (SD) & & $55.85 \pm 15.2$ & $59.88 \pm 13.9$ & 0.33 \\
\hline WHOQOL-BREF (psychological), Mean (SD) & & $51.56 \pm 15.4$ & $52.34 \pm 11.8$ & 0.84 \\
\hline WHOQOL-BREF (social relationships), Mean (SD) & & $54.70 \pm 17.5$ & $56.62 \pm 17.1$ & 0.69 \\
\hline WHOQOL-BREF (environment), Mean (SD) & & $60.07 \pm 10.8$ & $61.61 \pm 13.1$ & 0.65 \\
\hline
\end{tabular}

DUREL: Duke Religion Index; Trait Anxiety Inventory (STAI-Trait); BECK: Beck Depression Inventory; WHOQOL-BREF: abbreviated quality of life instrument; SD: standard deviation.

Table 2

Clinical outcomes in anxiety participants receiving the Spiritist "passe" and controls.

\begin{tabular}{|c|c|c|}
\hline & Control Mean (SD) & Spiritist “passe” Mean (SD) \\
\hline \multicolumn{3}{|l|}{ Trait Anxiety Inventory (STAI-Trait) ${ }^{\mathrm{a}}$} \\
\hline Baseline & $52 \pm 9.5$ & $50 \pm 9$ \\
\hline Week 4 & $43.4 \pm 13.7^{*}$ & $40.8 \pm 9.3^{*}$ \\
\hline Week 8 & $46.1 \pm 10.7^{*}$ & $37.1 \pm 10.9^{*, * *}$ \\
\hline \multicolumn{3}{|l|}{ Beck Depression Inventory (BECK) ${ }^{\mathrm{a}}$} \\
\hline Baseline & $17.4 \pm 8.1$ & $17 \pm 7.6$ \\
\hline Week 4 & $13.6 \pm 8.8^{*}$ & $11.1 \pm 6.9^{*}$ \\
\hline Week 8 & $11.8 \pm 7.5^{*}$ & $9.1 \pm 7.1^{*}$ \\
\hline \multicolumn{3}{|l|}{ WHOQOL-BREF (physical health)a } \\
\hline Baseline & $55.8 \pm 15.2$ & $59.8 \pm 13.9$ \\
\hline Week 4 & $60.4 \pm 14.6^{*}$ & $68.2 \pm 15.5^{*}$ \\
\hline Week 8 & $61.4 \pm 17.4^{*}$ & $68.8 \pm 17.0^{*, * *}$ \\
\hline \multicolumn{3}{|l|}{ WHOQOL-BREF (psychological)a } \\
\hline Baseline & $51.5 \pm 15.4$ & $52.3 \pm 11.8$ \\
\hline Week 4 & $57.2 \pm 13.3^{*}$ & $60.2 \pm 14.7^{*}$ \\
\hline Week 8 & $59.7 \pm 15.8^{*}$ & $66.0 \pm 14.6^{*}$ \\
\hline \multicolumn{3}{|l|}{ WHOQOL-BREF (social relationships)a } \\
\hline Baseline & $54.7 \pm 17.6$ & $56.6 \pm 17.1$ \\
\hline Week 4 & $58.3 \pm 17.9$ & $62.5 \pm 16.3$ \\
\hline Week 8 & $59.8 \pm 17.3$ & $64.6 \pm 19.9$ \\
\hline \multicolumn{3}{|l|}{ WHOQOL-BREF (environment) ${ }^{\mathrm{a}}$} \\
\hline Baseline & $60.1 \pm 10.8$ & $61.6 \pm 13.1$ \\
\hline Week 4 & $60.7 \pm 12.9$ & $68.1 \pm 14.8$ \\
\hline Week 8 & $60.3 \pm 13.3$ & $66.5 \pm 13.7^{* *}$ \\
\hline Participants with anxiety at 8 weeks ${ }^{\mathrm{b}}$ & $63 \%$ & $17.4 \%^{* * *}$ \\
\hline
\end{tabular}

SD: standard deviation.

a Mixed-models analysis.

b Anxiety defined as STAI-trace $>41$.

${ }_{*}^{*} \mathrm{p}<0.05 \times$ baseline.

*** $\mathrm{p}=0.05 \times$ control group.

(DUREL, BECK, WHOQOL-BREF) outcome measures were compared between groups using a repeated-measures model (linear mixed model) with treatment and time as fixed effects. Statistical significance was set at $\mathrm{p}<0.05$.

\section{Results}

Participants were enrolled in this trial between June 2014 and October 2015, and were followed up until December 2015. Of 97 individuals screened, 65 were randomized and 50, who completed the 8-week follow-up, were included in the final analysis (Fig. 1).

Participant characteristics at baseline were similar in both groups. Average age was $44 \pm 15$ years in the intervention group, and $47 \pm 16$ years in the control group. In both groups the major- ity of participants were white females. The predominant religion was Catholicism. There were no differences in DUREL scores for organizational religiosity, non-organizational religiosity and intrinsic religiosity between groups. Baseline depression (BECK), anxiety (STAI-trait) and quality of life (WHOQOL-BREF) scores were similar in both groups (Table 1 ).

\subsection{Primary endpoint}

Decreasing STAI-trait anxiety scores were observed in both groups throughout the study $(\mathrm{p}<0.0001$ at the end of the study compared to baseline). A more significant reduction in STAI-trait anxiety scores was seen in the Spiritist "passe" group compared to the control group, $\mathrm{p}=0.017$ (Fig. 2, Table 2). 

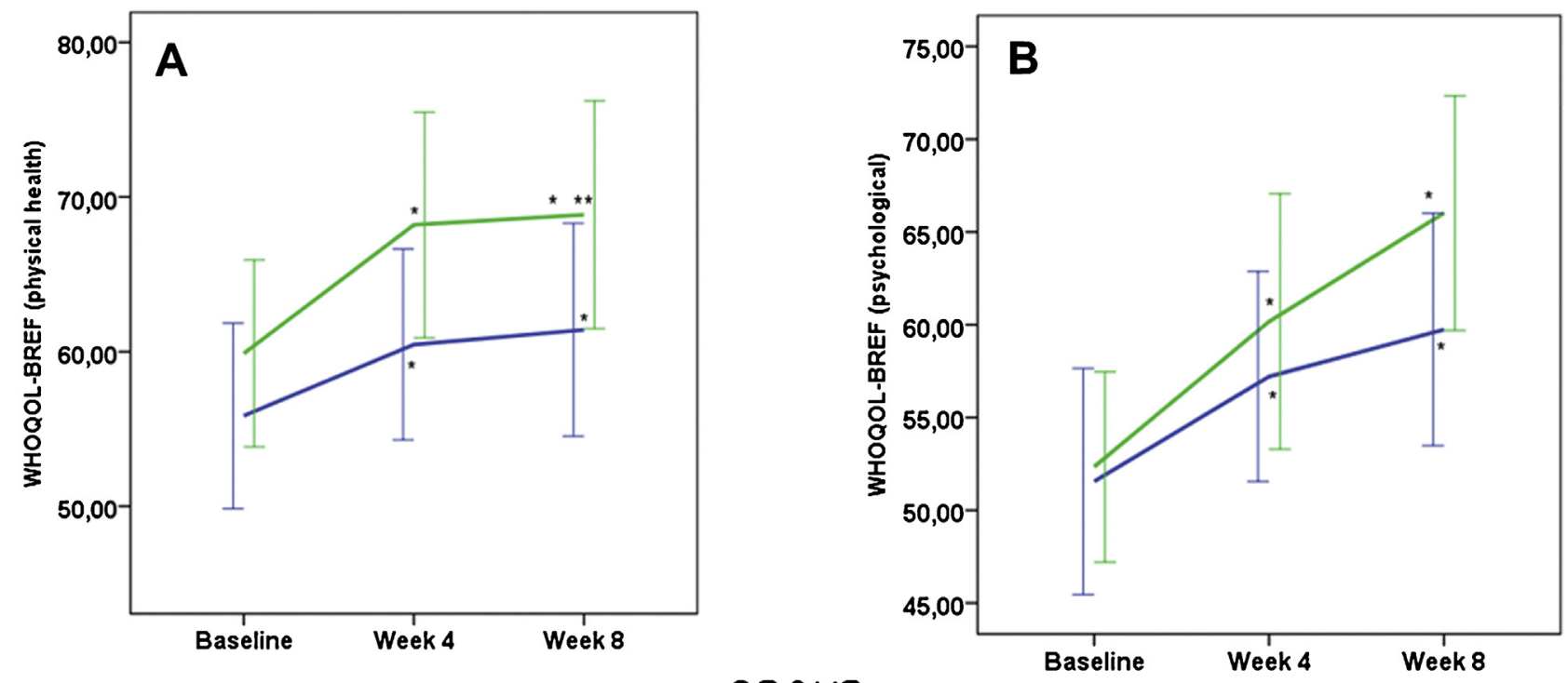

\section{GROUP}

control

spiritist "passe"
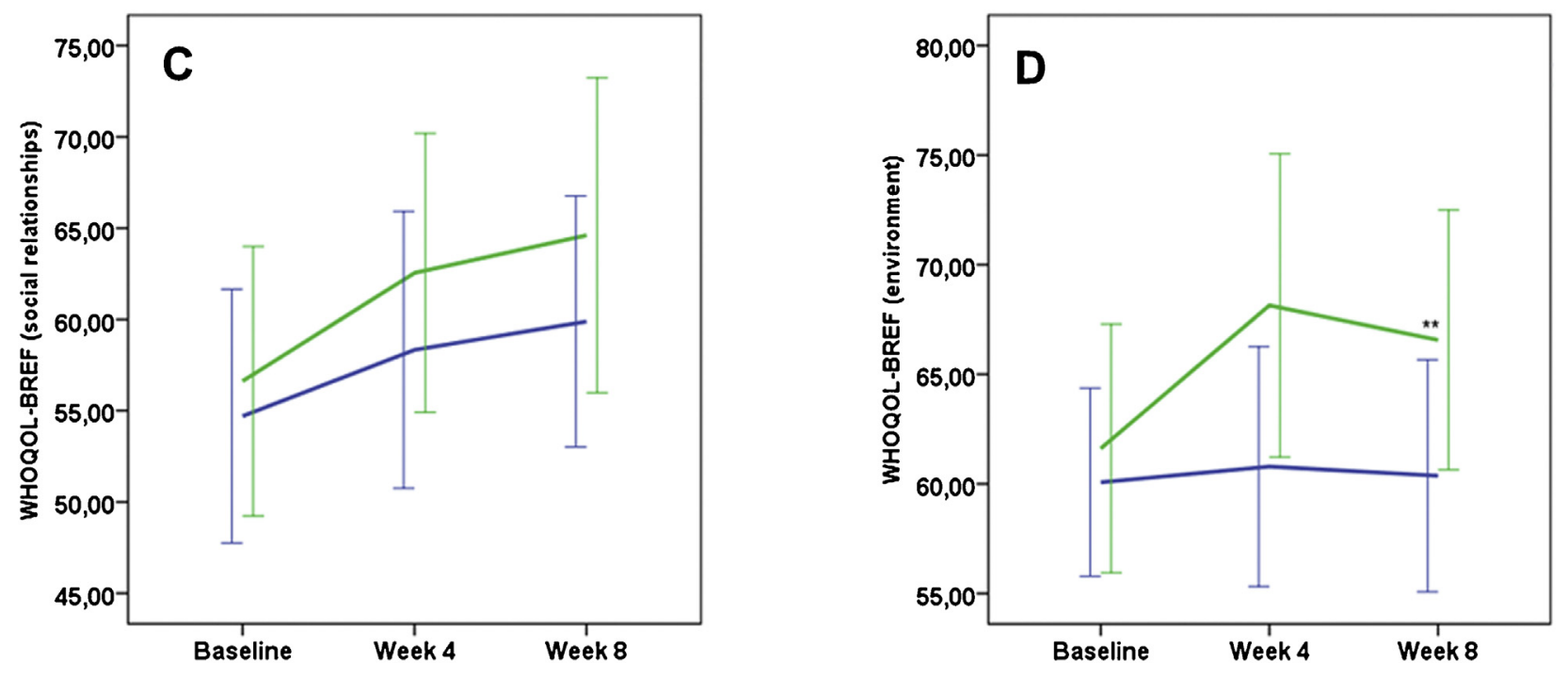

Fig. 4. Abbreviated quality of life instrument (WHOQOL-BREF) scores in anxiety participants receiving the Spiritist "passe" (green line) and controls (blue line) over the eight weeks of study. (A) WHOQOL-BREF (physical health); (B) WHOQOL-BREF (psychological health); (C) WHOQOL-BREF (social relationships); (D) WHOQOL-BREF (environment). ${ }^{*} \mathrm{p}<0.05 \times$ baseline; ${ }^{* *} \mathrm{p}=0.05 \times$ control group. (For interpretation of the references to color in this figure legend, the reader is referred to the web version of this article.)

After eight weeks, $17 \%$ of intervention participants and $63 \%$ of controls still showed anxiety (STAI-trait score $>41)(p=0.001)$.

\subsection{Secondary endpoint}

Decreasing Beck depression inventory scores were observed in both groups throughout the study $(\mathrm{p}<0.0001$ at the end of the study compared to baseline) with no difference between groups (Fig. 3, Table 2).

WHOQOL-BREF quality of life scores for the physical health domain improved in both groups during the study $(p=0.044)$. Improvement, however, was more accentuated in the Spiritist "passe" group $(\mathrm{p}=0.018)$. Scores for the psychological domain improved in both groups $(\mathrm{p}=0.001)$. There were no differences between groups in scores for the social relationships domain over time. Scores for the environmental domain improved only in the Spiritist "passe" group ( $\mathrm{p}=0.035$ ) (Table 2, Fig. 4).

\section{Discussion}

In this study, exposure to the Spiritist "passe" reduced anxiety and improved quality of life in the physical health and environmental domains. This is the first study to demonstrate the effectiveness of the Spiritist "passe" using a prospective randomized controlled trial design; prior clinical studies have been limited to descriptions of the spiritual treatment. ${ }^{18}$ Recent review studies on energy therapies, such as qigong, Johrei, ${ }^{3}$ polarity therapy, pranic healing, Reiki, ${ }^{4}$ Therapeutic Touch, prayer, and the Spiritist "passe", 5,18 have 
yielded inconclusive results because of the wide variety of methods used; medical conditions treated; outcome measures employed; and control interventions used. ${ }^{9,11,27,28}$

The Spiritist "passe", defined as "a transfusion of psychic energy", is the laying on of hands allegedly connected with a spiritual dimension. ${ }^{18}$ This alleged connection with a spiritual dimension is what differentiates the Spiritist "passe" from other biofield therapies. A recently published experimental study has demonstrated the effectiveness of the Spiritist "passe" on the growth of bacterial colonies of Escherichia Coli. The authors observed that, compared to control cultures, cultures receiving the Spiritist "passe" showed significantly reduced bacterial growth when the "passe" was applied with such intention. ${ }^{5}$ Such study has been recognized as the first experimental evidence of the effectiveness of the Spiritist "passe", which is largerly used in Brazil.

According to the literature, complementary therapeutic medicine can be effective in reducing anxiety. Johnson et al., in an analysis of retrospective data obtained from medical records, found that the use of integrative medicine reduced anxiety in $54.8 \%$ of cardiovascular inpatients, with mind-body and energy therapies, traditional Chinese medicine, and combination therapies being more effective than bodywork therapies. ${ }^{29}$ Anderson et al. reported that Healing Touch administered once a day after bariatric surgery decreased pain, nausea, and anxiety symptoms. ${ }^{30}$ Their study, however, had a quasi-experimental design as they used a non-concurrent comparison group. Pike et al., using a biofield therapy modality known as IRECA (Istituto di Ricerca sull'Energia Cosmica Applicata), observed significantly reduced anxiety and enhanced left-anterior activation of the cerebral cortex in the treatment group. ${ }^{31}$ Nonetheless, similarly to this present work, their study had a prospective controlled design.

In this study, there was a $82.6 \%$ reduction in anxiety in the intervention group using only non-pharmacological approaches. This reduction in anxiety may be attributed exclusively to the study intervention because no patient was receiving therapeutic drugs or concurrent psychological assistance. Anxiety reduction was also observed in the sham therapy group, but this is an expected results in studies of anxiety using placebo. ${ }^{32,33}$ Pollack et al. using pharmacological therapy to treat generalized anxiety disorder, demonstrated a reduction in anxiety with sertraline compared to placebo, but differences between groups were slight. ${ }^{32}$ In this study, anxiety reduction of greater magnitude was found in the intervention group with no side effects.

The modest effects produced by pharmacological therapies with greater side-effects have favored the use of an increasing number of alternative therapies to treat anxiety with non-pharmacological approaches. Such alternative therapies include cognitive-behavioural, ${ }^{34}$ psychological and biofield therapies. ${ }^{11,18,30}$ In a systematic review, Mayo-Wilson et al. found that individual cognitive-behavioural therapy, which has fewer side-effects, was superior to pharmacological approaches. ${ }^{34}$ Moreover, according to a model-based economic analysis, cognitive behavioural therapy appears to be more cost-effective than pharmacological interventions for social anxiety disorder. ${ }^{35}$

In addition to anxiety reduction, our results showed reduction in depression symptoms, as evidenced by the lower Beck Inventory scores observed at the end of the study. Likewise, quality of life scores also improved in three of four domains. Thus, anxiety and depression symptoms were reduced, and quality of life was improved in the intervention group.

One of the strengths of this work is its prospective randomized blind design. Moreover, potential confounding factors were avoided by using participants receiving no pharmacological, behavioural or psychological therapy.

Study limitations included the modality of the therapy investigated, which requires specialized training. Only two therapists with 5 years of experience participated in this study. However, different outcomes might have been observed with less experienced therapists. Additionally, the sample size was small, and there was no means to assess participant blinding. Finally, the study population consisted of individuals with anxiety, not clinical patients presenting with anxiety disorders.

\section{Conclusion}

This small pilot study found improved anxiety scores in participants exposed to the Spiritist "passe" as compared with controls. However, additional larger studies are needed to assess possible mechanisms and to determine the effects of the Spiritist "passe" energy therapy in clinical populations, while assessing for the effectiveness of blinding procedures.

\section{Authors' contributions}

Cavalcanti RS, Bravin AM and Banin VB conceived the study. Habernmann MC, Haberman F and Andrade LGM, drafted the manuscript. Daher SR and Padula NAMR designed the Spiritist "passe" intervention. All authors contributed to the study design and protocol preparation. All authors have read and approved the final manuscript.

\section{Author disclosure}

There are no competing financial interests.

\section{Acknowledgements}

The authors acknowledge the contribution of Alfredo Zavatti, Joel Pereira Almeida, Ana Carolina Tristão, Gustavo Gonçalves Yogolare, Gustavo Nicolodi Augusto, Nuno Emanuel Silva and Caroline Yuki Hayashi in the acquisition of data.

\section{References}

1. Tindle HA, Davis RB, Phillips RS, Eisenberg DM. Trends in use of complementary and alternative medicine by us adults: 1997-2002. Altern Ther Health Med. 2005;11:42-49.

2. Ni H, Simile C, Hardy AM. Utilization of complementary and alternative medicine by United States adults: results from the 1999 national health interview survey. Med Care. 2002;40:353-358.

3. Laidlaw TM, Naito A, Dwivedi P, Hansi NK, Henderson DC, Gruzelier JH. The influence of $10 \mathrm{~min}$ of the Johrei healing method on laboratory stress. Complement Ther Med. 2006:14:127-132.

4. Miles P, True G. Reiki-review of a biofield therapy history, theory, practice, and research. Altern Ther Health Med. 2003;9:62-72.

5. Lucchetti G, de Oliveira RF, Gonçalves JP, Ueda SM, Mimica LM, Lucchetti AL. Effect of Spiritist passe (Spiritual healing) on growth of bacterial cultures. Complement Ther Med. 2013;21:627-632.

6. Buzzetti R, Hinojosa-Kurtzberg M, Shea TJ, Ibuki Y, Sirakis G, Parthasarathy S. Effect of Johrei therapy on sleep in a murine model. Explore (NY). 2013;9:100-105.

7. Abe K, Ichinomiya R, Kanai T, Yamamoto K. Effect of a Japanese energy healing method known as Johrei on viability and proliferation of cultured cancer cells in vitro. J Altern Complement Med. 2012:18:221-228.

8. Jhaveri A, Walsh SJ, Wang Y, McCarthy M, Gronowicz G. Therapeutic Touch affects DNA synthesis and mineralization of human osteoblasts in culture. J Orthop Res. 2008;26:1541-1546.

9. Astin JA, Harkness E, Ernst E. The efficacy of distant healing: a systematic review of randomized trials. Ann Intern Med. 2000;132:903-910.

10. Hammerschlag R, Marx BL, Aickin M. Nontouch biofield therapy: a systematic review of human randomized controlled trials reporting use of only nonphysical contact treatment. J Altern Complement Med. 2014;20:881-892.

[11]. Joyce J, Herbison GP. Reiki for depression and anxiety. Cochrane Database Syst Rev. 2015;4:CD006833, http://dx.doi.org/10.1002/14651858.CD006833.pub2.

12. Thrane S, Cohen SM. Effect of Reiki therapy on pain and anxiety in adults: an in-depth literature review of randomized trials with effect size calculations. Pain Manag Nurs. 2014;15:897-908.

13. Moreira-Almeida A. History of Spiritist madness in Brazil. Hist Psychiatry. 2005; $16: 5-25$. 
14. Lucchetti G, Aguiar PR, Braghetta CC, Vallada CP, Moreira-Almeida A, Vallada H. Spiritist psychiatric hospitals in Brazil: integration of conventional psychiatric treatment and spiritual complementary therapy. Cult Med Psychiatry. 2012:36:124-135.

15. Lucchetti G, Daher JC, Landoli D, Gonçalves JPB, Lucchetti ALG. Historical and cultural aspects of the pineal gland: comparison between the theories provided by Spiritism in the 1940 and the current scientific evidence. Neuro Endocrinol Lett. 2013;34:745-755.

16. Lucchetti G, Lucchetti AL, Bassi RM, Nobre MR. Complementary spiritist therapy: systematic review of scientific evidence. Evid Based Complement Altern Med. 2011;2011:835945, http://dx.doi.org/10.1155/2011/835945 [Epub May 11, 2011].

17. Gasiorowska A, Navarro-Rodriguez T, Dickman R, et al. Clinical trial: the effect of Johrei on symptoms of patients with functional chest pain. Aliment Pharmacol Ther. 2009;29:126-134.

18. Lucchetti AL, Peres MF, Vallada HP, Lucchetti G. Spiritual treatment for depression in Brazil: an experience from Spiritism. Explore (NY). 2015;11:377-386.

19. Spielberger CD, Gorsuch RL, Lushene R. Manual for the state-trait anxiety inventory. Palo Alto, CA: Consulting Psychologistis Press; 1983.

20. Biaggio AMB. Desenvolvimento da forma em português do Inventário de Ansiedade Traço-Estado (IDATE) de Spielberger. Arq Bras Psicol. 1980;32:106-118.

21. Beck AT, Ward CH, Mendelson M, Mock J, Erbaugh J. An inventory for measuring depression. Arch Gen Psychiatry. 1961;4:561-571.

22. Gorenstein C, Andrade L. Validation of a Portuguese version of the Beck Depression Inventory and the state-trait anxiety inventory in Brazilian subjects. Braz J Med Biol Res. 1996;29:453-457.

23. The World Health Organization Quality of Life Assessment (WHOQOL): development and general psychometric properties. Soc Sci Med. 1998;46:1569-1585.

24. Fleck MP, Chachamovich E, Trentini C. Development and validation of the Portuguese version of the WHOQOL-OLD module. Rev Saude Publica. 2006;40:785-791.
25. Koenig HG, Büssing A. The duke university religion index (DUREL): a five-Item measure for use in epidemological studies. Religions. 2010;1:78-85.

26. Lucchetti G, Granero Lucchetti AL, Peres MF, Leão FC, Moreira-Almeida A, Koenig HG. Validation of the duke religion index: DUREL (Portuguese version). J Religion Health. 2012;51:579-586.

27. Abbot NC. Healing as a therapy for human disease: a systematic review. J Altern Complement Med. 2000;6:159-169.

28. Lee MS, Pittler MH, Ernst E. Effects of Reiki in clinical practice: a systematic review of randomised clinical trials. Int J Clin Pract. 2008;62:947-954.

29. Johnson JR, Crespin DJ, Griffin KH, et al. The effectiveness of integrative medicine interventions on pain and anxiety in cardiovascular inpatients: a practice-based research evaluation. BMC Complement Altern Med. 2014;13:14-486.

30. Anderson JG, Suchicital L, Lang M, et al. The effects of healing touch on pain, nausea, and anxiety following bariatric surgery: a pilot study. Explore (NY). 2015;11:208-216.

31. Pike C, Vernon D, Hald LA. Asymmetric activation of the anterior cerebral cortex in recipients of IRECA: preliminary evidence for the energetic effects of an intention-based biofield treatment modality on human neurophysiology. $J$ Altern Complement Med. 2014;20:780-786.

32. Pollack MH, Zaninelli R, Goddard A, et al. Paroxetine in the treatment of generalized anxiety disorder: results of a placebo-controlled, flexible-dosage trial. J Clin Psychiatry. 2001;62:350-357.

33. Brawman-Mintzer O, Knapp RG, Rynn M, Carter RE, Rickels K. Sertraline treatment for generalized anxiety disorder: a randomized, double-blind, placebo-controlled study. J Clin Psychiatry. 2006;67:874-881.

34. Mayo-Wilson E, Dias S, Mavranezouli I, et al. Psychological and pharmacological interventions for social anxiety disorder in adults: a systematic review and network meta-analysis. Lancet Psychiatry. 2014;1:368-376.

35. Mavranezouli I, Mayo-Wilson E, Dias S, et al. The cost effectiveness of psychological and pharmacological interventions for social anxiety disorder: a model-based economic analysis. PLoS One. 2015;10:e0140704. 